\title{
BMJ Substandard and counterfeit medicines: Open a systematic review of the literature
}

\author{
Tariq Almuzaini, Imti Choonara, Helen Sammons
}

To cite: Almuzaini T, Choonara I, Sammons $H$. Substandard and counterfeit medicines: a systematic review of the literature. BMJ Open 2013;3:e002923. doi:10.1136/bmjopen-2013002923

- Prepublication history and additional material for this paper is available online. To view these files please visit the journal online (http://dx.doi.org/10.1136/ bmjopen-2013-002923)

Received 28 March 2013 Revised 10 July 2013 Accepted 11 July 2013

Academic Division of Child Health, University of Nottingham, Derbyshire Children's Hospital, Derby, UK

\footnotetext{
Correspondence to

Tariq Almuzaini; mzxta@exmail.nottingham. ac.uk
}

\section{ABSTRACT}

Objective: To explore the evidence available of poorquality (counterfeit and substandard) medicines in the literature.

Design: Systematic review.

Data sources: Databases used were EMBASE, MEDLINE, PubMed and the International Pharmaceutical Abstracts, including articles published till January 2013.

Eligibility criteria: Prevalence studies containing original data. WHO definitions (1992) used for counterfeit and substandard medicines.

Study appraisal and synthesis: Two reviewers independently scored study methodology against recommendations from the MEDQUARG Checklist. Studies were classified according to the World Bank classification of countries by income.

Data extraction: Data extracted: place of study; type of drugs sampled; sample size; percentage of substandard/counterfeit medicines; formulations included; origin of the drugs; chemical analysis and stated issues of counterfeit/substandard medicines.

Results: 44 prevalence studies were identified, 15 had good methodological quality. They were conducted in 25 different countries; the majority were in low-income countries (11) and/or lower middle-income countries (10). The median prevalence of substandard/counterfeit medicines was $28.5 \%$ (range 11-48\%). Only two studies differentiated between substandard and counterfeit medicines. Prevalence data were limited to antimicrobial drugs (all 15 studies). 13 studies involved antimalarials, 6 antibiotics and 2 other medications. The majority of studies $(93 \%)$ contained samples with inadequate amounts of active ingredients. The prevalence of substandard/counterfeit antimicrobials was significantly higher when purchased from unlicensed outlets $(p<0.000 ; 95 \% \mathrm{Cl} 0.21$ to 0.32 ). No individual data about the prevalence in upper middle-income countries and high-income countries were available.

Limitations: Studies with strong methodology were few. The majority did not differentiate between substandard and counterfeit medicines. Most studies assessed only a single therapeutic class of antimicrobials.

Conclusions: The prevalence of poor-quality antimicrobial medicines is widespread throughout Africa and Asia in lower income countries and lower middle-income countries. The main problem identified was inadequate amounts of the active ingredients.

\section{ARTICLE SUMMARY}

Article focus

- To systematically review prevalence studies on substandard and counterfeit medicines published in the literature.

\section{Key messages}

- The prevalence of substandard/counterfeit antimicrobials is high throughout Africa and Asia in lower income countries and lower middle-income countries.

- The prevalence of substandard/counterfeit medicines was significantly higher in the unlicensed markets.

- Inadequate amounts of active ingredients were the largest problem identified.

Strengths and limitations of this study

- The article demonstrates a systematic review of prevalence studies on substandard/counterfeit medicines, with assessment of their quality before inclusion.

- This review is limited by the methodology used in the included studies, such as sampling methods, the assessment of a single therapeutic class (antimicrobial drugs), as well as scarce packaging analysis data to differentiate between counterfeit and substandard medicines.

\section{INTRODUCTION}

Counterfeiting in pharmaceutical products is an increasing worldwide dilemma with a profound impact on lower income countries (LIC) and lower middle-income countries (LMIC). ${ }^{12}$ It is also becoming an issue in high-income countries (HIC). ${ }^{3-5}$

There is no clear, agreed international definition of counterfeit medicines. ${ }^{6}$ The most widely used definition in the literature, in the last two decades, is that given in 1992 by the WHO. ${ }^{7}$ This defines a counterfeit medicine as a medicine which is deliberately and fraudulently mislabelled with respect to identity and/ or source. Counterfeiting can apply to branded and generic products. Counterfeit products may include the following: the correct ingredients, the wrong ingredients, no active ingredients, insufficient ingredients or 
fake packaging (ie, misleading about its origin or authenticity). ${ }^{7}$ Substandard medicines are defined as genuine medicines which have failed to pass the quality measurements and standards set for them. These quality standard tests have been derived from the official pharmacopoeias. ${ }^{8}$ In 2011, the WHO member states chose to include counterfeit and substandard medicines under the new term 'substandard/spurious/falsely-labelled/falsified/counterfeit medical products' (SSFFC). This new term, however, has been questioned recently ${ }^{6}$ as it is felt not to distinguish sufficiently between the different illegitimate drug categories (such as counterfeit and substandard) that require different monitoring and solutions.

According to The Pharmaceutical Security Institute data, the incidents of counterfeit medicines increased dramatically from 196 incidents in 2002 to 2018 incidents in 2012. ${ }^{9}$ The data are, in part, a reflection of adequate law enforcement and regulatory oversight in countries where these reports came from. ${ }^{10}$ However, this figure would be even higher if resource-poor countries had adequate surveillance systems. Drug regulatory authorities and pharmaceutical companies hold records on counterfeit medicines, yet most are inaccessible. ${ }^{6} 10$ More insight into the problem can be gained from prevalence studies published in the literature. ${ }^{10}$ Thus, our objective was to systematically review prevalence studies published in the literature.

\section{METHODS}

A literature search was carried out using the following medical databases: EMBASE (data range 1974-January 2013), MEDLINE (data range 1948-January 2013), PubMed (data range 1950-January 2013) and International Pharmaceutical Abstracts (data range 1970-January 2013). A preliminary search for MeSH terms associated with published prevalence studies was conducted trying to choose the most specific and sensitive words for the search strategy. Specific therapeutic areas, such as antimalarials, were recognised and added as additional terms to increase sensitivity; the search, however, was not limited to these categories. The search terms included: 'fake', 'counterfeit', 'substandard' or 'falsified' and have been combined with 'drugs', 'medicines', 'pharmaceuticals', 'antimicrobials', 'antimalarials' or 'antibiotics'. The search strategy is detailed in online supplementary table S1. The review was performed in accordance with the PRISMA statement. ${ }^{11}$

The eligibility criteria were any studies (irrespective of language) that evaluated the prevalence of substandard or counterfeit medicines within a defined area. Studies which discussed analytical methods for the identification of these drugs as well as reviews, opinion papers, letters and comments were set as exclusion criteria.

\section{Data collection process and data items}

All abstracts were screened and evaluated against the inclusion and exclusion criteria. Where there was a doubt or the abstract was not available, the full text was obtained to determine inclusion. Full articles were then retrieved and a manual search of the references was performed. The following data were extracted independently (TA): place of the study; type of drugs sampled; sample size; percentage of counterfeit/substandard medicines; dosage forms included the following: chemical analysis; origin of the drugs and stated issues of substandard/counterfeit medicines (defined in online supplementary table S2). The number of medicines sampled and those that failed quality tests were also extracted from studies that included samples from licensed outlets (ie, public and private sectors) and unlicensed outlets (ie, informal markets). Study selection and data extraction were double-checked independently (HS) before inclusion.

Studies were classified according to the World Bank classification of income level as follows: LIC, LMIC, upper middle-income countries (UMIC) and HIC. ${ }^{12}$ Any study that contained information on more than one country was classified in the mixed group.

Substandard and counterfeit medicines are both recognised as poor-quality medicines. Chemical and packaging analysis is required to conclude if a medicine is substandard or counterfeit. This, however, is difficult and rarely reported. ${ }^{13}$ Therefore, the term substandard/ counterfeit medicine is used in this review unless studies formally assessed packaging to differentiate medicines into these two different categories.

\section{Quality evaluation assessment}

Quality assessment of studies was conducted to try to minimise bias from the methodology used to collect data. The methodology of all identified studies were assessed against 12 criteria adapted from a previous published review (box 1). ${ }^{14}$ These criteria were given in the methodology section of the MEDQUARG (Medicine Quality Assessment Reporting Guidelines) Checklist of items to be addressed in reports of surveys of medicine quality. Two reviewers (TA and HS) performed the

\section{Box 1 Quality assessment criteria}

1. Timing and location of study clearly stated.

2. Definition of counterfeit or substandard medicines used mentioned.

3. Type of outlets sampled.

4. Sampling design and sample size calculation described.

5. Type and number of dosage units purchased per outlet.

6. Random sampling used.

7. Information on who collected the samples (were mystery shoppers applied?)

8. Packaging assessment performed.

9. Statistical analysis described.

10. Chemical analysis clearly described.

11. Details on method validation.

12. Chemical analysis performed blinded to packaging 
evaluation independently. If there was any disagreement level, an independent third person (IC) was consulted. As there has been no cut-off limit specified, all studies that scored 6 or more were included as a subset of the studies that have good methodological strength, and therefore there was less chance of bias in their results.

\section{Statistical analysis}

The median prevalence of substandard/counterfeit medicines was analysed for each income level group. Comparison of the prevalence in licensed (public and private sectors) and unlicensed (informal markets) outlets was performed using the Fisher exact test for proportions. A significant difference was defined at a $\mathrm{p}$ value $<0.05$.

\section{RESULTS}

A total of 44 studies of the prevalence of substandard/ counterfeit medicines were identified. The number of articles screened and assessed is detailed in figure 1. After independent assessment, there was a 95\% agreement level between the two assessors against the criteria specified for the quality assessment of the study methodology (box 1). No study fulfilled all 12 criteria. One study met 10 criteria, whereas 29 studies met only 5 criteria or less (figure 2 and online supplementary table S3). Fifteen studies fitted the prespecified criteria of scoring 6 or above ${ }^{15-29}$ and were included in the analysis.

\section{Study methodology}

All studies were designed to select drug samples from a target geographical region. These included drugs

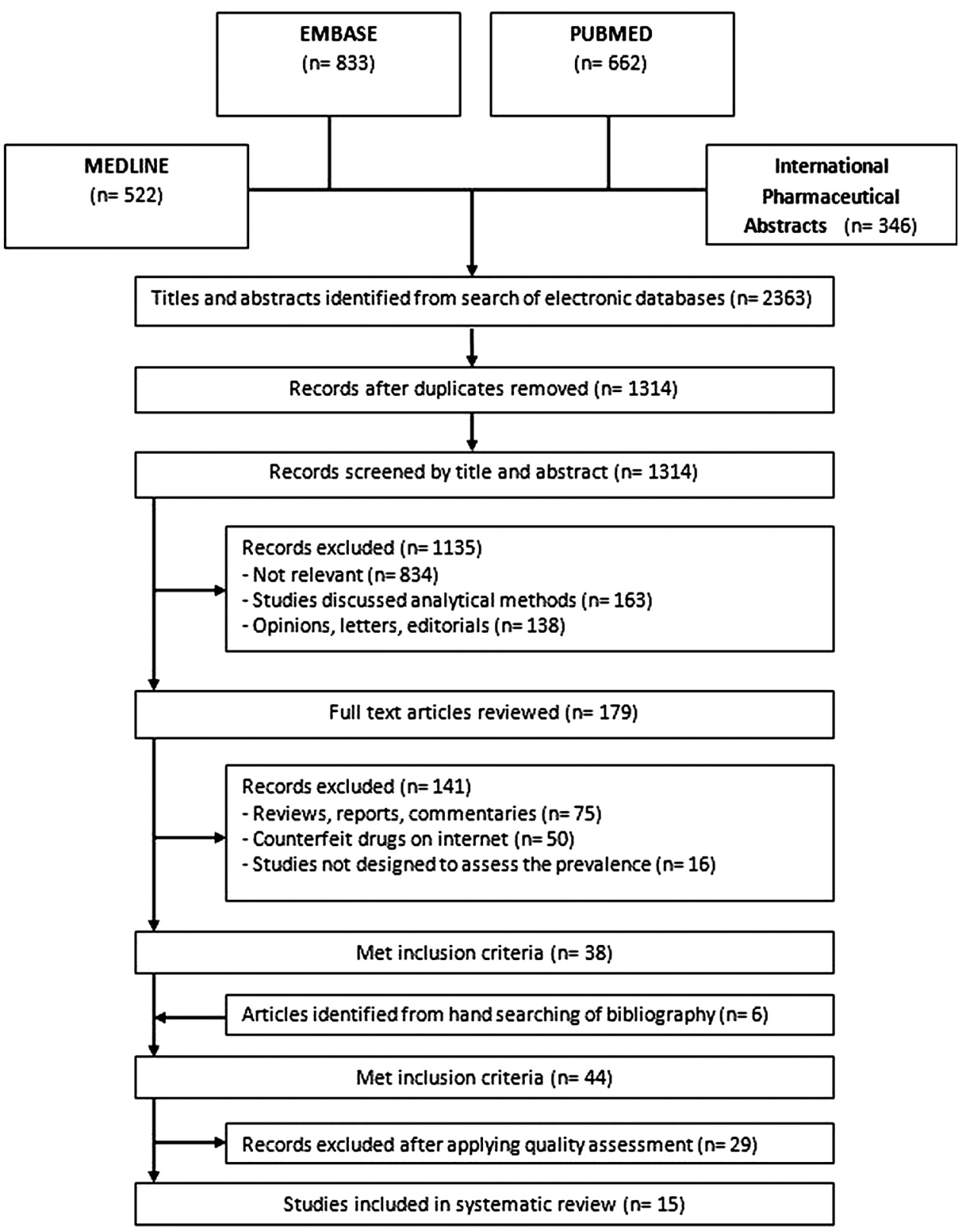

Figure 1 Flow diagram of search and review process. 
Figure 2 Quality assessment criteria for methodology of included studies.

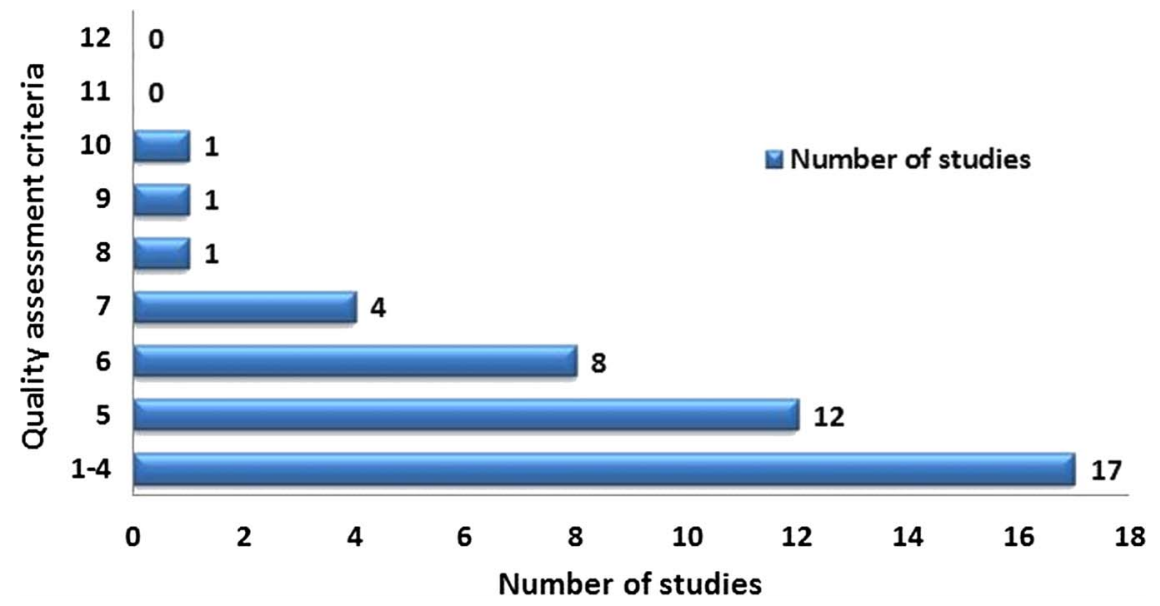

sampled from the public (ie, pharmacy hospitals and primary healthcare centres), private and/or informal (ie, market stalls and street sellers) sectors (see online supplementary table S4).

More than half of the studies used a convenience sampling method, in which investigators collected medicines from only accessible outlets. Only four studies used random sampling methods, in which investigators collected samples from outlets that were randomly chosen from a complete or registered list or outlets in a defined area. $^{16171922}$ Information on the person collecting the samples was provided by 12 studies. ${ }^{15}{ }^{17-23} 25-28$ Samples in these studies were purchased by national collaborators, behaving as normal clients, in situations where the seller had no indication as to the purpose of the purchases.

Methods used for drugs analysis were variable according to the type of test, dosage form and drug analysed. Generally, analysis of these samples was carried out with regard to pharmacopoeia specifications (see online supplementary table S4). Non-pharmacopoeial drugs were analysed in accordance with specifications and particular methods of their manufactures in order to evaluate the quality of these drugs.

The majority of the studies were conducted by investigators from different academic and research institutions $(60 \%)$, with $40 \%$ from multilateral organisations (eg, WHO and UNICEF).

\section{Overview of the studies and prevalence of substandard/ counterfeit medicines}

Fifteen studies were conducted in 25 different countries, mainly in Africa and Asia. Twenty-one were either LIC or LMIC. All 15 studies assessed the quality of antimicrobial drugs. Antimalarial drugs were the most extensively studied group of medicines (13 studies). Six studies included antibiotics and two studies included other therapeutic agents, paracetamol, ranitidine, salbutamol, diazepam and analgesics in their sampling process. ${ }^{17}{ }^{23}$ Only two studies considered paediatric formulations (ie, syrup and suspension) in their sampling process. ${ }^{22} 24$
The median prevalence of substandard/counterfeit medicines was $28.5 \%$ (range 11-48\%). The median prevalence of substandard/counterfeit medicines for each income level was similar in LIC (24\%), LMIC (38\%) and the mixed group (28.5\%; table 1$)$. The majority of the studies (8) were conducted in sub-Saharan Africa, where the prevalence of substandard/counterfeit medicines ranged from $12.2 \%$ to $48 \%$ (median $34 \%$ ). This was similar in the five studies conducted in South Asia, range $11-44 \%$ (median 22\%). This prevalence is mainly representative of antimicrobial drugs, as these accounted for the bulk of the tested samples. Details for each individual study are given in online supplementary table S4.

Only two studies from Southeast Asia performed packaging analysis of the samples collected. ${ }^{15} 28$ The prevalence of counterfeit drugs was $16 \%$ and $43 \%$ of antimalarials, respectively. The other studies were not designed to detect counterfeit medicines. However, the possibility of counterfeiting was raised in five of these studies as some of the samples had the wrong or no active ingredients. ${ }^{17} 1921-23$

\section{Stated issues of substandard/counterfeit medicines}

The assessment of drugs was made through special procedures and methods derived from official pharmacopoeias. The most common issues with substandard/ table 2. Inadequate amount of active ingredients was the most frequent problem reported.

\section{Prevalence according to where medicines are purchased} Where patients purchase their medicines may affect the prevalence of substandard/counterfeit medicines. Five studies were identified in this review that sampled from licensed outlets (public and private sectors) and unlicensed outlets (informal markets; table 3). Four of these studies concerned antimalarials, ${ }^{15} 242627$ and one concerned antibiotics. ${ }^{23}$ The percentage of failed samples in unlicensed outlets was $51 \%$, whereas it was $24 \%$ in licensed outlets. The proportion of failed samples was significantly higher in the unlicensed markets $(\mathrm{p}<0.000 ; 95 \%$ CI 0.21 to 0.32$)$. Further details counterfeit drugs reported by these studies are shown in 
Table 1 The range of the prevalence of counterfeit and substandard medicines based on the World Bank classification of countries (by income level)

\begin{tabular}{|c|c|c|c|}
\hline $\begin{array}{l}\text { Income level } \\
\text { classification }\end{array}$ & Countries & $\begin{array}{l}\text { Number of } \\
\text { studies }\end{array}$ & $\begin{array}{l}\text { Prevalence of substandard/ } \\
\text { counterfeit medicines } \\
\text { Range } \% \text { (median \%) }\end{array}$ \\
\hline LIC & Lao PDR, Tanzania, Cambodia, Uganda & 4 & $12.2-44.5(24)$ \\
\hline LMIC & Indonesia, Nigeria, Cameroon & 4 & $18-48(38)$ \\
\hline UMIC & 0 & 0 & - \\
\hline $\mathrm{HIC}$ & 0 & 0 & - \\
\hline \multicolumn{4}{|l|}{ Mixed group } \\
\hline LIC & $\begin{array}{l}\text { Myanmar, Cambodia, Lao PDR, Ghana, Kenya, } \\
\text { Tanzania, Uganda, Madagascar, Mali, Mozambique, } \\
\text { Zimbabwe }\end{array}$ & 7 & $11-44(28.5)$ \\
\hline LMIC & $\begin{array}{l}\text { Vietnam, Thailand, Cameroon, Nigeria, Senegal, } \\
\text { Sudan, Armenia, Ukraine, Uzbekistan }\end{array}$ & & \\
\hline UMIC & Gabon, Azerbaijan, Belarus, Kazakhstan & & \\
\hline $\mathrm{HIC}$ & 0 & & \\
\hline
\end{tabular}

on the individual failure rate in the public and private sectors were not given in these studies.

\section{DISCUSSION}

The aim of this systematic review was to summarise the current data in the literature regarding substandard/ counterfeit medicines around the world. The results have shown that there is a significant problem in Africa and Asia, in LIC and LMIC, regarding antimicrobial medicines. Our findings highlight the lack of studies that exist outside of these regions and therapeutic classes. It also shows the lack of evidence available that specifically differentiates between substandard and counterfeit medicines. No individual data about the prevalence of these drugs in UMIC and HIC was available.

Our review shows a high prevalence of poor-quality antimicrobials. Most of the prevalence studies focused on antimicrobial medicines because of the considerable burden of infectious diseases in the study countries. This is in keeping with a recent commentary in the $B M J$ that highlighted substandard medicines as a priority

Table 2 Frequency of six different issues reported concerning the quality of the medicines tested

\begin{tabular}{lcc}
\hline & $\begin{array}{l}\text { Frequency of studies } \\
\text { containing samples with } \\
\text { Stated problem }\end{array}$ & $\begin{array}{l}\text { Per } \\
\text { cent }\end{array}$ \\
\hline $\begin{array}{l}\text { Inadequate amount } \\
\text { of active ingredient }\end{array}$ & 14 & 93 \\
$\begin{array}{l}\text { No active ingredient } \\
\text { Excessive amount of }\end{array}$ & 7 & \\
$\begin{array}{l}\text { active ingredient } \\
\text { Dissolution failure }\end{array}$ & 5 & 47 \\
$\begin{array}{l}\text { Wrong ingredient } \\
\text { Impurity }\end{array}$ & 4 & 40 \\
\hline
\end{tabular}

area in tropical diseases. ${ }^{30}$ Under-dosing of antimicrobials can enhance the survival of more resistant parasites and therefore emergence of drug resistance. ${ }^{31}{ }^{32}$ There was strong evidence in our results of samples with an inadequate amount of active ingredients $(93 \%$ of studies), absence of active ingredients (47\%) and dissolution failure (33\%), comparable to taking a medicine in low dose and therefore likely to cause treatment failure. If $10 \%$ of patients fail treatment, it is recommended by the WHO that there should be a change in malaria treatment policy. ${ }^{33}$ The amount of substandard/counterfeit medicines in the supply chain needs to be considered prior to this happening. Studies to assess the direct link between substandard/counterfeit drugs and drug resistance, however, have not been documented.

This review has shown that the prevalence of substandard/counterfeit antimicrobials reported was significantly higher in the unauthorised market. Unofficial sale of drugs in LIC and LMIC is a common practice and considered a serious public health problem. ${ }^{21} 34$ A survey carried out in Benin found that $86 \%$ of individuals interviewed thought that drugs purchased from unauthorised markets were of good quality. ${ }^{34}$ The high cost of genuine drugs has been the main driving force for people to seek cheaper drugs from unauthorised markets. ${ }^{21}$ Governments can play an important role in this matter by reducing taxes applied on medications. It has also to encourage domestic manufacturing of good quality and affordable generic drugs and to implement robust policies to ensure domestic market utilisation of these drugs. ${ }^{35} 36$

A large proportion of the studies identified were found to have a poor methodological quality. Only 15 of 44 studies identified met our quality inclusion criteria. 'Convenience sampling' was often preferred and investigators collected samples haphazardly based on what outlets were accessible. This method is convenient and inexpensive, and gives an initial assessment of the 
Table 3 Percentage failure of samples collected at different sectors

\begin{tabular}{|c|c|c|c|c|c|c|c|}
\hline \multirow[b]{2}{*}{ Country } & \multicolumn{3}{|c|}{$\begin{array}{l}\text { Licensed outlets (public and private } \\
\text { sectors) }\end{array}$} & \multicolumn{3}{|c|}{ Unlicensed outlets (informal market) } & \multirow[b]{2}{*}{ References } \\
\hline & $\begin{array}{l}\text { Total } \\
\text { number of } \\
\text { Samples }\end{array}$ & $\begin{array}{l}\text { Number } \\
\text { of failed } \\
\text { samples }\end{array}$ & $\begin{array}{l}\text { Percentage } \\
\text { of failed } \\
\text { samples }\end{array}$ & $\begin{array}{l}\text { Total } \\
\text { number of } \\
\text { Samples }\end{array}$ & $\begin{array}{l}\text { Number } \\
\text { of failed } \\
\text { samples }\end{array}$ & $\begin{array}{l}\text { Percentage } \\
\text { of failed } \\
\text { samples }\end{array}$ & \\
\hline $\begin{array}{l}\text { Cameroon, Ethiopia, } \\
\text { Ghana, Kenya, Nigeria, } \\
\text { Tanzania }\end{array}$ & 240 & 64 & 26.6 & 27 & 12 & 44.4 & 26 \\
\hline $\begin{array}{l}\text { Madagascar, Senegal, } \\
\text { Uganda }\end{array}$ & 144 & 41 & 28.4 & 53 & 23 & 43.4 & 27 \\
\hline Cambodia & 38 & 22 & 58 & 133 & 100 & 75 & 15 \\
\hline Myanmar & 215 & 34 & 16 & 23 & 20 & 87 & 23 \\
\hline $\begin{array}{l}\text { Gabon, Ghana, Kenya, } \\
\text { Mali, Mozambique, } \\
\text { Sudan, Zimbabwe }\end{array}$ & 229 & 52 & 23 & 136 & 37 & 27 & 24 \\
\hline Total & 866 & 213 & 24 & 372 & 192 & 51 & \\
\hline
\end{tabular}

problem faced (analogous to a case report), but is prone to bias and may not be representative of the target area studied. ${ }^{14}$ A more reliable and accurate measure involves an estimate of a sample size and selection of a random number of outlets from a complete list from that area. Only four studies were randomly selected from a complete list and only one calculated the sample size required. ${ }^{16}$ Information on the person collecting the samples, what is said to retailers and the behaviour at collection sites is also important, because if the seller realises that the 'customers' are performing a drug quality survey, this can affect their decision to offer substandard/counterfeit medicines for sale. Guidelines for surveys of the quality of medicines have been published and give clear standards for future studies. ${ }^{14}$

There are a number of international and national initiatives taking place to combat the problem of counterfeit and substandard medicines. INTERPOL, in cooperation with the World Customs Organisation (WCO) and $\mathrm{WHO}$, is working with national police forces in combating the illicit trade of medicines, targeting both illicit physical and online outlets. ${ }^{37} 38$ The Container Control Programme (CCP) established by the United Nations Office on Drugs and Crime (UNDOC) and WCO, to enhance inspection of containers for counterfeit goods, has become an important tool to counteract the traffic of counterfeit drugs. ${ }^{39}$ Recently, member states of the WHO have agreed on a new mechanism to tackle not only the problem of SSFFC but also to ensure the availability of quality, safe, efficacious and affordable medical products. ${ }^{40}$ However, more collaboration between different national and international organisations is needed to counteract this problem.

\section{Limitations and strengths}

This review has a number of limitations including only searching published and accessible databases. Some reports were confidential, unpublished or published solely for limited distribution. ${ }^{23}$ Some studies used different definitions and referred drug specifications to different pharmacopoeias. Furthermore, there have been inconsistencies in terms of drug sampling methods and the types of sector involved. All these factors make direct comparison difficult. Packaging analysis is important to confirm if a medicine is counterfeit or substandard. Currently, there is a scarcity of data to measure the prevalence of each problem individually. This is important as the causes and remedies are different. All the studies involved antimicrobials. The prevalence of counterfeit and substandard drugs in other therapeutic classes therefore remained unclear. In addition, data analysis and samples collected by investigators in some of these studies were not necessarily representative of a large target area, and thus the prevalence obtained cannot be extrapolated to the whole country studied. However, these studies give an insight into the problem and, following our assessment of methodology, give the best evidence currently available in the literature.

\section{CONCLUSION}

Substandard/counterfeit antimicrobial drugs represent a huge problem throughout Africa and Asia in LIC and LMIC, where the prevalence has been documented within studies. Antimicrobials, in their solid formulations, have been the most extensively studied group. Inadequate amounts of active ingredients were the main problem identified. Little consideration has been given to other therapeutic classes or paediatric formulations and this warrants further investigation. Well-designed prevalence studies, with adequate methodological details, are indeed required to reflect the actual prevalence.

Contributors TA and HS designed the search strategy. TA performed the literature search, screened the titles and abstracts and managed the references. HS independently double-checked the extracted data. TA and HS screened the retrieved papers against inclusion criteria and independently performed the quality evaluation assessment for the review. IC had the original idea for the study and interpreted the results. TA drafted the 
manuscript and IC and HS critically revised it. All authors approve of this final submitted version after their revision of the manuscript.

Funding This research received no specific grant from any funding agency in the public, commercial or not-for-profit sectors.

Competing interests None.

Provenance and peer review Not commissioned; externally peer reviewed.

Data sharing statement No additional data are available.

Open Access This is an Open Access article distributed in accordance with the Creative Commons Attribution Non Commercial (CC BY-NC 3.0) license, which permits others to distribute, remix, adapt, build upon this work noncommercially, and license their derivative works on different terms, provided the original work is properly cited and the use is non-commercial. See: http:// creativecommons.org/licenses/by-nc/3.0/

\section{REFERENCES}

1. Caudron JM, Ford N, Henkens M, et al. Substandard medicines in resource-poor settings: a problem that can no longer be ignored. Trop Med Int Health 2008;13:1062-72.

2. Newton PN, Green MD, Fernández FM. Impact of poor-quality medicines in the 'developing' world. Trends Pharmacol Sci 2010;31:99-101.

3. Mackey TK, Liang BA. The global counterfeit drug trade: patient safety and public health risks. J Pharm Sci 2011;100:4571-9.

4. Liang B. Fade to black: importation and counterfeit drugs. Am J Law Med 2006;32:279-323.

5. European Commission. Report on EU customs enforcement of intellectual property rights: results at the EU border. 2011. http://ec. europa.eu/taxation_customs/resources/documents/customs/ customs controls/counterfeit_piracy/statistics/2012 ipr_statistics_en. pdf (accessed 23 May 2013)

6. Attaran A, Barry D, Basheer S, et al. How to achieve international action on falsified and substandard medicines. BMJ 2012;345:e7381.

7. WHO. Counterfeit drugs guidelines for the development of measures to combat counterfeit drugs. WHO/EDM/QSM/99.1. Geneva: WHO, 1999. http://whqlibdoc.who.int/hq/1999/WHO_EDM_QSM_99.1.pdf (accessed 10 Apr 2011).

8. WHO. What are substandard medicines? http://www.who.int/ medicines/services/counterfeit/faqs/06/en/ (accessed 23 May 2013).

9. PSI-Inc. (Pharmaceutical Security Institute). Counterfeit situation. http://www.psi-inc.org/incidentTrends.cfm (accessed 23 May 2013).

10. The Institute of Medicine (IOM). Countering the Problem of Falsified and Substandard Drugs report. 2013. http://www.iom.edu/Reports/ 2013/Countering-the-Problem-of-Falsified-and-Substandard-Drugs. aspx (accessed 23 May 2013).

11. Moher D, Liberati A, Tetzlaff J, et al. Preferred reporting items for systematic reviews and meta-analyses: the PRISMA statement. PLoS Med 2009;6:e1000097.

12. World Bank. How we Classify Countries. http://data.worldbank.org/ about/country-classifications (accessed 25 May 2013).

13. Newton PN, Amin AA, Bird C, et al. The primacy of public health considerations in defining poor quality medicines. PLoS Med 2011;8: e1001139.

14. Newton PN, Lee SJ, Goodman C, et al. Guidelines for field surveys of the quality of medicines: a proposal. PLoS Med 2009;6:e1000052.

15. Lon CT, Tsuyuoka R, Phanouvong S, et al. Counterfeit and substandard antimalarial drugs in Cambodia. Trans $R$ Soc Trop Med Hyg 2006;100:1019-24.

16. Kaur $\mathrm{H}$, Goodman $\mathrm{C}$, Thompson $\mathrm{E}$, et al. A nationwide survey of the quality of antimalarials in retail outlets in Tanzania. PLOS ONE 2008;3:e3403.

17. Syhakhang L, Lundborg CS, Lindgren $\mathrm{B}$, et al. The quality of drugs in private pharmacies in Lao PDR: a repeat study in 1997 and 1999. Pharm World Sci 2004;26:333-8.

18. Ogwal-Okeng J, Owino E, Obua C. Chloroquine in the Ugandan market fails quality test: a pharmacovigilance study. Afr Health Sci 2003;3:2-6.

19. Onwujekwe $\mathrm{O}$, Kaur $\mathrm{H}$, Dike $\mathrm{N}$, et al. Quality of anti-malarial drugs provided by public and private healthcare providers in south-east Nigeria. Malar J 2009;8:22.

20. Hadi U, van den Broek P, Kolopaking E, et al. Cross-sectional study of availability and pharmaceutical quality of antibiotics requested with or without prescription (Over The Counter) in Surabaya, Indonesia. BMC Infect Dis 2010;10:203.
21. Basco LK. Molecular epidemiology of malaria in Cameroon. XIX. Quality of antimalarial drugs used for self-medication. Am J Trop Med Hyg 2004;70:245-50.

22. Taylor RB, Shakoor O, Behrens $\mathrm{RH}$, et al. Pharmacopoeial quality of drugs supplied by Nigerian pharmacies. Lancet 2001;357:1933-6.

23. Wondemagegnehu E. Counterfeit and substandard drugs in Myanmar and Vietnam. Geneva: World Health Organization, 1999. WHO/EDM/QSM/99.3. http://apps.who.int/medicinedocs/pdf/s2276e/ s2276e.pdf (accessed 23 May 2013).

24. Maponga C, Ondari C. The quality of antimalarials. A study in selected African countries. Geneva: World Health Organization, 2003. WHO/EDM/PAR/2003.4. http://apps.who.int/medicinedocs/pdf/ s4901e/s4901e.pdf (accessed 23 May 2013).

25. Shakoor O, Taylor RB, Behrens RH. Assessment of the incidence of substandard drugs in developing countries. Trop Med Int Health 1997;2:839-45.

26. Sabartova J, Toumi A, Ondari C. Survey of the quality of selected antimalarial medicines circulating in six countries of sub-Saharan Africa. Geneva: World Health Organization, 2011. WHO/EMP/QSM/ 2011.1. http://www.who.int/medicines/publications/WHO QAMSA report.pdf (accessed 23 May 2013).

27. A collaborative study by the WHO and DQI. Survey of the quality of selected antimalarial medicines circulating in Madagascar, Senegal, and Uganda. November 2009. http://apps.who.int/ medicinedocs/documents/s17069e/s17069e.pdf (accessed 23 May 2013).

28. Dondorp AM, Newton PN, Mayxay M, et al. Fake antimalarials in Southeast Asia are a major impediment to malaria control: multinational cross-sectional survey on the prevalence of fake antimalarials. Trop Med Int Health 2004;9:1241-6.

29. Sabartova J, Nathanson E, Polishchuk O. Survey of the quality of anti-tuberculosis medicines circulating in selected newly independent states of the former Soviet Union. Geneva: World Health Organization, 2011. WHO/EMP/QSM/2011.2. http://apps. who.int/medicinedocs/documents/s19053en/s19053en.pdf (accessed 23 May 2013)

30. Dorlo TPC, Ravinetto RM, Beijnen JH, et al. Commentary: substandard medicines are the priority for neglected tropical diseases. BMJ 2012;345:e7518.

31. Terlouw DJ, Nahlen BL, Courval JM, et al. Sulfadoxinepyrimethamine in treatment of malaria in Western Kenya: increasing resistance and underdosing. Antimicrob Agents Chemother 2003;47:2929-32.

32. Barnes $\mathrm{KI}$, Watkins WM, White NJ. Antimalarial dosing regimens and drug resistance. Trends Parasitol 2008;24:127-34.

33. WHO. Guidelines for the treatment of malaria. 2nd edn. 2010. http://whqlibdoc.who.int/publications/2010/9789241547925_eng.pdf (accessed 25 May 2013).

34. Abdoulaye I, Chastanier H, Azondekon A. Survey on the illicit drug market in Cotonou, Benin in March 2003. Med Trop (Mars) 2006;66:573-6.

35. Wertheimer Al, Norris J. Safeguarding against substandard/ counterfeit drugs: mitigating a macroeconomic pandemic. Res Social Adm Pharm 2009;5:4-16.

36. Health Action International (HAl). Medicine pricing matters. Taxing essential medicines-a sick tax that hinders access to treatment. December 2009. http://www.haiweb.org/medicineprices/29012010/ MPM_6.pdf (accessed 11 June 2013).

37. Interpol. Pharmaceutical crime. 2012. COM/FS/2012-01/DCO-04. http://www.interpol.int/content/download/3902/37957/version/ 17/file/Factsheets_EN_jun2012_DCO04.pdf (accessed 24 May 2013).

38. WCO. International operation combats the online supply of counterfeit and illegal medicines. November 2009. http://www. wcoomd.org/en/media/newsroom/2009/november/internationaloperation-combats-the-online-supply-of-counterfeit-and-illegalmedicines.aspx (accessed 24 May 2013).

39. UNDOC. UN drugs and crime office, World Customs Organization make a dent in counterfeit goods and drug shipments. 2012. http:// www.unodc.org/unodc/en/press/releases/2012/June/un-drugs-andcrime-office-world-customs-organization-make-a-dent-on-counterfeitgoods-and-drug-shipments.html (accessed 24 May 2013).

40. WHO. Substandard/spurious/falsely-labelled/falsified/counterfeit medical products: report of the Working Group of Member States. 2012. http://apps.who.int/gb/ebwha/pdf_files/WHA65/A65_23-en.pdf (accessed 23 May 2013).

41. WHO. New global mechanism to combat Substandard/Spurious/ Falselylabelled/ Falsified/Counterfeit medical products. 2012. http:// www.who.int/medicines/news/TRA-SE_EMP.pdf (accessed 23 May 2013). 